\title{
Green solvents for membrane manufacture: Recent trends and perspectives
}

\author{
Dooli Kim and Suzana P. Nunes \\ King Abdullah University of Science and Technology (KAUST), Biological and Environmental \\ Science and Engineering Division (BESE), Advanced Membranes and Porous Materials Center, \\ 23955-6900 Thuwal, Saudi Arabia
}

\begin{abstract}
Membrane fabrication highly relies on solution processes. Environmental and health concerns are driving the investigation of alternative green solvents to substitute classical toxic ones. Recent contributions to this topic are reviewed, comparing advantages and drawbacks of manufacturing membranes using water, bio-sourced solvents, non-toxic synthetic organic solvents and ionic liquids as the most explored.
\end{abstract}

\section{Introduction}

Environmental awareness and health concern have driven strict recommendations of emission control in the industry and other sectors directly affecting our lives. There is an urge to implement zero-emissions of greenhouse gases in 2050 in an attempt to stop or revert the global temperature increase. Carbon capture alone is not sustainable enough. It is essential to act in advance. Sustainability in industrial processes and a holistic foresight are needed. There is a recognized need for actions to conserve our natural capital of fresh water, clean air and the biodiversity and pollution minimization is essential for that. Membrane technology has a great opportunity to become a crucial tool toward process intensification in sustainable chemical and pharmaceutical industries, as well as toward sustainable water purification and reuse. Their contribution to water desalination and reuse is undeniable and extending their application to industrial separations could save great part of the energy demanded by traditional unit operations like distillation. Membranes could be particularly attractive in designing greener continuous processes of separation for dehydration, in-line concentration, crystallization and pharmaceutical drugs purification. [1]

However, beyond the contribution to the environmental and economic improvement of separation processes, the membrane manufacturing industry itself needs to be part of the 
transition. Reviews on the sustainability of nanomaterials and chemical processes [2], green membrane manufacture [3] have been recently published. Bio-based and biodegradable polymers [4] are among "green" materials. Derivatives of natural polymers have been used since the introduction of membrane-based separations. However, processing materials such as cellulose in solution for many years required harsh solvents. Working with large scale recyclable polymers is a possibility, [5] as long again as the processing itself is green. Conversion/recovery [6] of polymer materials is of increasing importance and we ideally should come with solutions that permit a full cycle of circular chemistry for membrane materials production, as well as recycling methods for module transformation and reuse. Nevertheless, reducing the exposure of workers to harmful chemicals in the production is an important point.

This review is specifically focused on recent trends in green solvents as strategy for sustainable membrane fabrication. Most commercial polymeric membranes are produced by solution processes such as non-solvent induced phase separation (NIPS) or by thermal induced phase separation (TIPS), which also includes solvents. Unfortunately, widespread solvents in the membrane industry, such as N,N-dimethyl formamide (DMF), N,N-dimethyl acetamide (DMAc) and N-methyl pyrrolidone (NMP) are considered substances of very high concern (SVHC) and toxic to reproduction. Special authorization is currently needed for their use in the industry and restricted conditions apply. For instance, in Europe, the regular long-term ( $8 \mathrm{~h}$ daily) exposure to DMF or DMAc needs to be lower than $15 \mathrm{mg} / \mathrm{m}^{3}$; for NMP is $40 \mathrm{mg} / \mathrm{m}^{3}$, hexane $72 \mathrm{mg} / \mathrm{m}^{3}$, toluene $192 \mathrm{mg} / \mathrm{m}^{3}$, methanol $260 \mathrm{mg} / \mathrm{m}^{3}$, cyclohexane $700 \mathrm{mg} / \mathrm{m}^{3}$. This has motivated the search for alternative green solvents for membrane fabrication. The awareness is slowly growing. The number of publications on "green solvents for membranes" evolved in the Web of Science from 5 to above 200 per year in the last 20 years. A more specific distribution of publications on current green solvent approaches for membranes is shown in Figure 1, with the expected advantages of each one of them. A green solvent is expected to be non-toxic, non-volatile, and/or derived from renewable sources.

\section{Membrane production without solvents}

Ideally, processes of membrane manufacture without solvents could be the most environmentally beneficial technologies. However, membranes have been produced for several decades mostly by 
solution processes. Reverse osmosis and nanofiltration membranes are mainly produced by nonsolvent induced phase separation (NIPS) as integral asymmetrically porous or as thin-film composite (TFC) membranes, prepared by interfacial polymerization (IP) coating, all steps requiring large amount of solvents. Substituting these technologies by another one without solvents, keeping similar surface area production rate would not be realistic at this moment. However, technologies without solvent are already available for diverse applications. Wellestablished is the preparation of microfiltration membranes from semi-crystalline polymers such as polytetrafluorethylene, polyolefin and poly(vinylidene fluoride) (PVDF) by extrusion followed by stretching. A growing expectation is toward micro- and nanofabrication methods, such as 3D printing. The resolution of the method for ultrafiltration (UF) porous membranes is still not high enough, but the method progresses fast and it is expected that it will soon be more applied for membranes. [7] 3D printing is being used also for ceramic and might open perspectives for more versatile and cost-effective process for this class of materials. [8] Resolution is here an important factor, as well. Isoporous membranes with pore size down 700 $\mathrm{nm}$ have been recently manufactured without solvents, using a combination of photolithography and dry reactive ion etching. [9] The method for lower pore sizes is being currently optimized.

\section{Membrane production using green solvents}

\section{Membrane production using water}

The most convenient solvent would be water. Some recent developments are listed in Table 1. An innovative method has been introduced by the de Vos's group [10-11] on the membrane preparation using water as casting solvent. The phase separation and pore formation are mainly driven by changes in $\mathrm{pH}$. It is a very attractive concept, since water would be the greenest solvent. A similar procedure using water as solvent and promoting phase separation by altering the ionic strength has been proposed by the Wessling's group. [12] The methods have a broad potential. Stability might be an issue to improve. These methods applied to a relatively restrict class of functionalized polymers in a certain window of conditions. Further development of methods based on aqueous solutions would be very beneficial. 


\section{Green solvents for membranes}
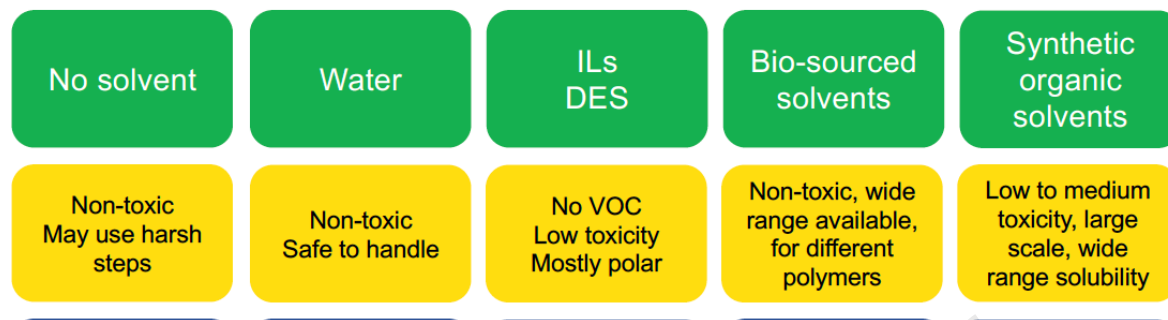

\section{Non-toxic, wide} range available, for different polymers

$$
\begin{aligned}
& \text { Low to medium } \\
& \text { toxicity, large } \\
& \text { scale, wide }
\end{aligned}
$$
range solubility

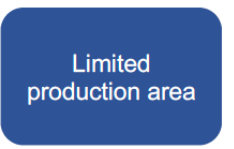

Limited dissolution for many solvents

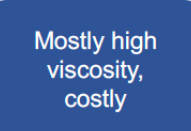

Not always available in large scale

Not always

renewable and completely nontoxic

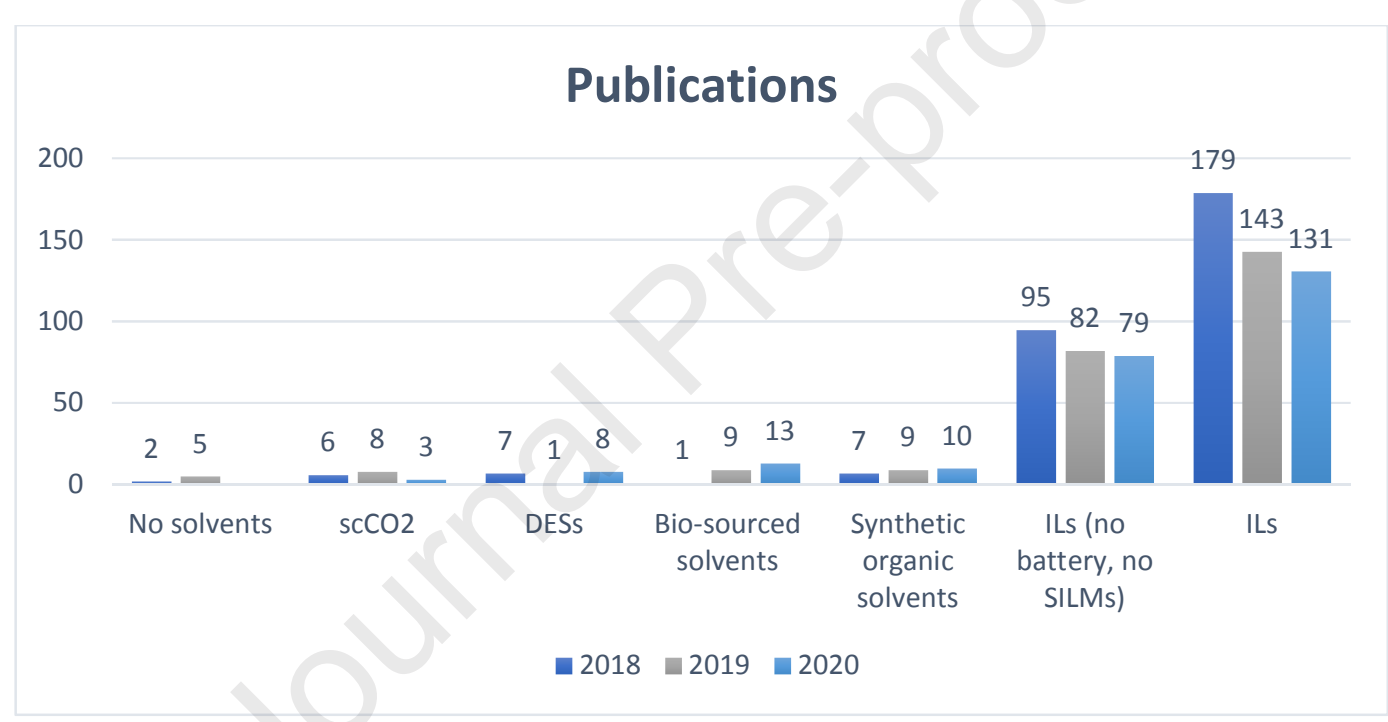

Figure 1. Key properties, safety of green solvents used for membrane production, and publications count from 2018 to 2020 in Scopus strictly linked to the corresponding solvents applied to polymeric membranes. 
Table 1. Water and bio-sourced solvents for membrane manufacture.

\begin{tabular}{|l|l|l|l|l|}
\hline Solvent & Polymer & Method & Process & Ref. \\
\hline \multirow{3}{*}{ Water } & PSS/PAH & $\begin{array}{l}\text { Aqueous phase } \\
\text { separation } \\
\text { (APS)- } \\
\text { pH induced } \\
\text { phase separation }\end{array}$ & NF/MF & {$[10-$} \\
& \multirow{2}{*}{ PSS/PDADMAC } & $\begin{array}{l}\text { Salt induced } \\
\text { phase inversion }\end{array}$ & NF/UF & {$[12]$} \\
\cline { 2 - 6 } & PSS/QVP-C2 & $\begin{array}{l}\text { Salt induced } \\
\text { phase inversion }\end{array}$ & UF & {$[13]$} \\
\cline { 2 - 6 } & Sodium Alginate & Dip-coating & NF & {$[14]$} \\
\hline Bio-sourced solvents & \multicolumn{5}{|l|}{} & \\
\hline Methyl lactate/2-methyl tetrahydrofuran & CA & NIPS & NF & {$[15]$} \\
\hline Coconut oil (Decanoic acid) & Modified PA & IP & NF & {$[16]$} \\
\hline$\gamma$-Valerolactone & PSU & NIPS & UF & {$[17]$} \\
\hline$\gamma$-Valerolactone and glycerol deriv. & Various & NIPS & NF-MF & {$[18]$} \\
\hline Cyrene & PES, PVDF & NIPS/VIPS & UF/MF & {$[19]$} \\
\hline Isosorbide & PVDF, PES & NIPS, & UF/MF & {$[20]$} \\
\hline N,N-dimethyl lactamide & NIPS/VIPS & NIPS & UF & {$[21]$} \\
\hline Succindiamide & PES & NIPS & Not tested & {$[22]$} \\
\hline Glycerol deriv./2-MeTHF & PVDF, PES, PAI & NIPS & NF & {$[23]$} \\
\hline Dimethyl isosorbide (DMI) & CA & VIPS/NIPS & MF & {$[24]$} \\
\hline
\end{tabular}

Membrane processes: microfiltration (MF), ultrafiltration (UF), nanofiltration (NF)

Methods: temperature induced phase separation (TIPS); non-solvent induced phase separation (NIPS); interfacial polymerization (IP); vapor induced phase separation (VIPS)

Polymers: poly(vinylidene fluoride) (PVDF), cellulose acetate (CA), cellulose diacetate (CDA), poly(lactic acid) PLA, polysulfone (PSU), poly(ether sulfone)(PES), poly(amide imide) (PAI), sulfonated polystyrene (PSS), poly(sodium 4styrenesulfonate) (PSS), poly(allylamine hydrochloride) (PAH), poly(diallyldimethylammonium chloride) (PDADMAC), and poly(N-ethyl-4-vinylpyridinium) (QVP-C2) 
Table 2. "Greener" synthetic organic solvents for membrane manufacture.

\begin{tabular}{|c|c|c|c|c|}
\hline Solvent & Polymer & Method & Process & Ref. \\
\hline \multicolumn{5}{|l|}{ Non-ionic solvents } \\
\hline Dimethyl sulfoxide (DMSO) & PVDF & VIPS & MF & [26] \\
\hline DMSO EVOL & PES & NIPS/VIPS & MF & [27] \\
\hline \multirow[t]{4}{*}{ Rhodiasolv® PolarClean } & PES & NIPS & MF & {$[28]$} \\
\hline & PES, PSU, CA & NIPS & NF/UF & [29] \\
\hline & PVC-g-PEGMA & NIPS & UF & [30] \\
\hline & PVDF/PSU & NIPS & UF/MF & {$[31]$} \\
\hline Butyl Acetate & LDPE & TIPS & UF/MF & [32] \\
\hline Organic Carbonates & Various & NIPS & $\mathrm{NF}$ & [33] \\
\hline Dimethyl Carbonate (DMC) & Bamboo fiber, PLA & Solvent evaporation & $\begin{array}{l}\text { Non- } \\
\text { woven }\end{array}$ & [34] \\
\hline \multicolumn{5}{|l|}{ Ionic liquids } \\
\hline [BMIM]Tf2N & PA & 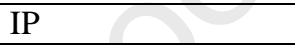 & $\mathrm{NF}$ & [35] \\
\hline \multirow[t]{3}{*}{ [EMIM]OAc } & Cellulose & NIPS/dip-coating & $\mathrm{NF} / \mathrm{UF}$ & $\begin{array}{l}{[36-} \\
38]\end{array}$ \\
\hline & Chitin/cellulose & $\begin{array}{l}\text { NIPS } \\
\text { Electrospinning }\end{array}$ & Not tested & $\begin{array}{l}{[39]} \\
{[40]}\end{array}$ \\
\hline & PMIA/PEI & NIPS/crosslinking & $\mathrm{NF}$ & [41] \\
\hline \multirow[t]{3}{*}{ [EMIM]DEP } & Cellulose & NIPS & NF/UF & [38] \\
\hline & 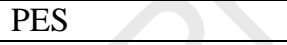 & NIPS & NF/UF & [42] \\
\hline & Polytriazole & NIPS & NF/UF & [43] \\
\hline [EMIM]SCN, [BMIM]SCN & EXTEM & NIPS & UF & [44] \\
\hline [EMIM]Tf2N & $\begin{array}{l}\text { Poly(ionic } \\
\text { liquid)/zeolite }\end{array}$ & $\begin{array}{l}\text { Casting and cross- } \\
\text { linking }\end{array}$ & GS & [45] \\
\hline
\end{tabular}

Polymers: poly(lactic acid) PLA, poly(ethylene imine) (PEI), poly(vinyl chloride)-g-poly(ethylene glycol methacrylate) (PVC-gPEGMA), poly(m-phenylene isophthalamide) (PMIA), poly (ether imide sulfone) (EXTEM)

Ionic liquids: 1-butyl-3-methylimidazolium bis(trifluoromethyl sulfonyl)imide ([BMIM]Tf2N), 1-ethyl-3-methylimidazolium acetate ([EMIM]OAc), 1-3-dimethylimidazolium dimethylphosphate ([MMIM]DMP), 1-ethyl-3-methylimidazolium diethylphosphate ([EMIM]DEP), 1-ethyl-3-methylimidalzolium thiocyanate ([EMIM]SCN), 1-butyl-3-methylimidalzolium thiocyanate ([BMIM]SCN)

\section{Membrane production using bio-sourced solvents}

Water is not a universal solvent for all membrane-relevant polymers. The next green alternative is the use of bio-sourced solvents. The membrane fabrication by NIPSs using various biosourced solvents have been demonstrated by different groups (Table 1). Figoli's group has been proposing different solvents, like Cyrene ${ }^{\mathrm{TM}}$ [19] and isosorbide [20]. Other bio-sourced solvents are methyl lactate [15], $\gamma$-valerolactone [17-18], N,N-dimethyl lactamide [21], succindiamide [22], glycerol derivatives [23], 2-methyl tetrahydrofuran (2-MeTHF). [15] Glycerol derivatives such as monoacetin, diacetin, triacetin, glycerol- formal together with 2-MeTHF as a co-solvent can be used for NF membrane fabrication. Rasool et al. [23] analyzed thermodynamic and kinetic aspects, depending on the combination of glycerol derivates and 2-MeTHF and the 
concentration of CA, and examined the resultant morphology of membranes.

Bio-sourced solvents have been also used for membrane production in combination with other methods, e.g. dimethyl isosorbide (DMI), combining VIPS and NIPS [24]. Decanoic acid has been introduced instead of other organic solvents for interfacial polymerization [16].

\section{Membrane production using DMSO}

Table 2 lists recent reports on membrane manufacture using synthesized organic solvents with low toxicity. The closest substitute for DMF, NMP and DMAc in terms of polarity and capability of dissolving similar polymers is DMSO. The primary source for DMSO is renewable. DMSO is derived from the wood pulp industry, produced by the oxidation of dimethyl sulfide. It is considered a non-toxic chemical, although some reasons for concern have been recently identified of in vitro. [25] The strong characteristic smell is a clear disadvantage. DMSO $\mathrm{EVOL}^{\mathrm{TM}}$ is a new grade engineered to change the characteristic smell to a much more pleasant one. Procedures for preparation of polyethersulfone (PES) and poly(vinylidene fluoride) (PVDF) membranes using DMSO as solvent have been published by Figoli's and Ulbricht's groups.[26,27]

\section{Membrane production using non-ionic synthetic organic solvents}

Among the emerging solvents for membrane fabrication, Rhodiasolv® PolarClean has now been explored by different researchers with increasing interest, applied to a variety of polymers, such as PVDF, polysulfone (PSU), polyethersulfone (PES) and others, as shown in Table 2. This is a polar aprotic solvent constituted by methyl-5-(dimethylamino)-2-methyl-5-oxopentanoate and its diamide derivative in a 20:1 ratio. It is considered non-toxic and therefore has great chances of being even more applied in the industry. The whole production life cycle still has to be fully considered. Particularly interesting is a recent morphology reported for membranes prepared by blending PVDF and PSU in a PolarClean solution. [32] Dimethyl carbonate and other organic carbonates are also quite versatile and an excellent alternative for dissolving polymers of normal interest for membrane manufacture as pure solvent or in combination with others [34]. Butyl acetate is found in fruits, but is also chemically synthesized. It has been recently demonstrated as alternative to much more toxic xylene to dissolve polyethylene in the thermal induced phase separation (TIPS) membrane manufacture. [32] 


\section{Membrane production using ionic liquids}

Ionic liquids (ILs) consist of cations and anions. Due to the low lattice energy between cations and anions, they exist as liquid. Since they do not have a measurable vapor pressure, the level of produced toxic volatile organic compounds (VOCs) is almost zero. From this point of view, ILs are considered green solvents, although we cannot deny the existence of some controversy in terms of not completely investigated toxicity in water or the sustainability of their production life cycle assessment (LCA). [46] There is a broad variety of ionic liquids and this increases the chances of identifying suitable matches for different polymers, as well as choosing those with highest levels of sustainability. Independent of the environmental aspect, ILs are particularly attractive, because they have the advantage of dissolving materials that have been hardly soluble in other solvents and have led to different morphologies and performance than achieved with other solvents. The best example is the capability of ILs to dissolve cellulose, which has been now explored by different research groups. [36-38] In the last years, the use of ILs has been extended to substitute polar organic solvents, such as DMF, DMAc, NMP, for the preparation of asymmetric porous membranes based in several polymers, by the NIPS method (Table 2).

Besides the application in NIPS, the Vankelecom's group [35] introduced ILs ([BMIM]Tf $\left.{ }_{2} \mathrm{~N}\right)$ as solvent for the organic phase in the preparation of a membrane selective layer by interfacial polymerization.

Furthermore, ILs have been long used as immobilized solvents within the porous support for supported ILs membranes for gas separation. Recently, the Noble's and Gin's groups [45] reported mixed matrix membranes (MMMs) for $\mathrm{CO}_{2} / \mathrm{CH}_{4}$ separation, prepared from poly(ionic liquid)/IL/zeolite. Dispersed solutions of a curable IL prepolymer and zeolite in [EMIM] $\mathrm{Tf}_{2} \mathrm{~N}$ were cast on a UF support membrane and then photo-crosslinked to form the membrane.

\section{Membrane production using deep eutectic solvents}

Deep eutectic solvents (DESs) consist of hydrogen bond acceptors (HBA) and donors (HBD) and many are of natural source. [47] In membrane production, they are mainly used as immobilized solvents within the pores of preformed supports [48], for surface cleaning and modification of thin film composite (TFC) polyamide RO membranes [49], for the pretreatment of raw materials like silkworm fibers [50] and lignocellulosic biomass [51] to loosen and swell 
the structure of materials. DESs were also used as co-solvents or as additives mixed with DMF, NMP, DMAc for porous membrane fabrication.

\section{Outlook}

The main driving force for the transition into a more sustainable membrane production using green solvents is the concern on the health of the manufacturing staff and the risk of emissions to the environment. But the final move for implementation will be the establishment of environmental legislation in different countries. Until then, effective alternatives for the currently used solvents and processes have to be proposed and demonstrated. The main considerations are summarized in Figure 3. For membranes to continue to be a sustainable solution for separations, their performance and stability are still priorities in pore ranges varying from RO, NF to UF and MF. In many membrane applications, large areas are required and continuous manufacturing processes are necessary. The manufacturing methods available without solvents, such as lithography and 3D-printing can be successful for selected applications, but are far to provide the needed broad and large scale to cover the whole membrane technology spectrum. Therefore, solvent processes will continue to predominate. Production processes with green solvents should be optimized and ready. Good options have been already reported, each with advantages and drawbacks. For a solution process, the solubilization strength of the solvents and the extension of their applicability are essential aspects. The green manufacture will probably consist of a combination of solutions for selected classes of membranes. Water, is an attractive solution, but can serve as solvent for a limited class of materials. Bio-sourced solvents are advantageous as real green chemicals, with low or no toxicity, high biodegradability, but their success depends on their availability in large scale at accessible costs. Synthetic solvents with solvent strength closer to DMF and DMAc are those with more immediate consideration. Under this category are DMSO, PolarClean and ionic liquids, providing low toxicity to the operators during the manufacturing process and low environmental emissions. Nevertheless, for the holistic sustainability, the life cycle assessment of these solvents is also relevant, as well as the possibilities of recycling to secure zero-discharge. 


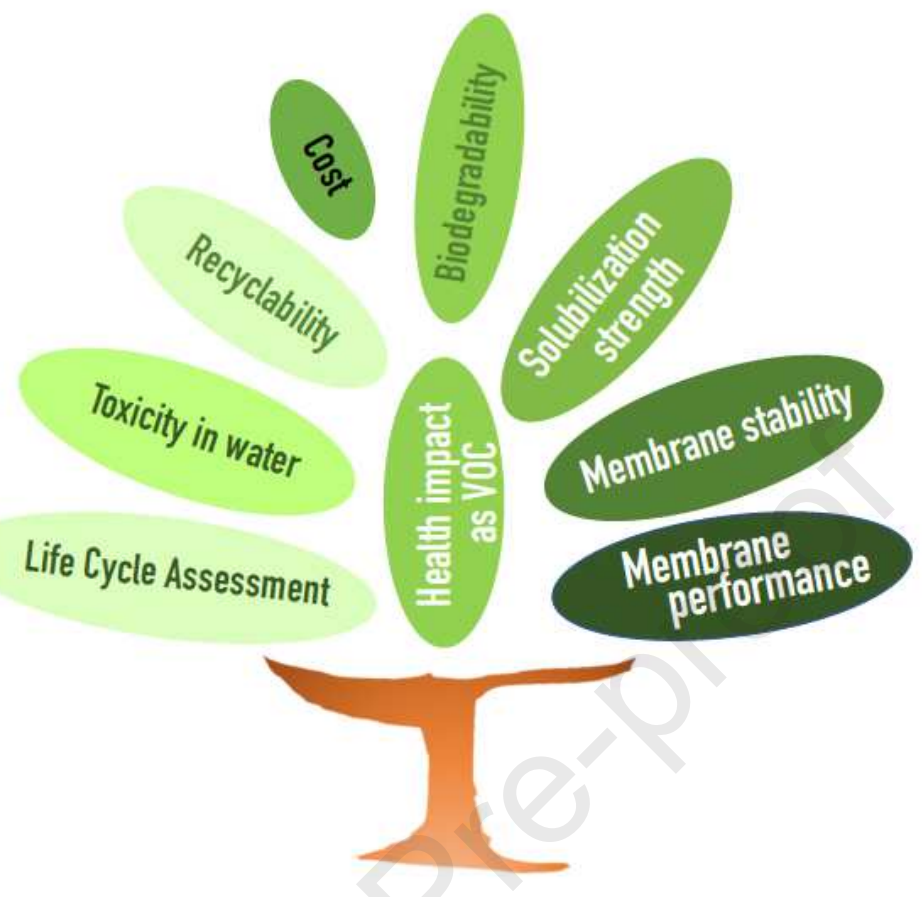

Figure 3. Relevant aspects for green solvent selection and implementation.

\section{Conflict of interest statement}

Nothing declared.

\section{Acknowledgements}

The authors thank King Abdullah University of Science and Technology (KAUST) for financial support. 


\section{References}

Papers of particular interest, published within the last two years are highlighted as:

- of special interest

$\bullet \bullet$ of outstanding interest

1. Rogers L, Jensen KF: Continuous manufacturing-the Green Chemistry promise? Green chemistry 2019, 21:3481-3498.

-• 2. Livingston A, Trout BL, Horvath IT, Johnson MD, Vaccaro L, Coronas J, Babbitt CW, Zhang X, Pradeep T, Drioli E: Challenges and Directions for Green Chemical Engineering-Role of

Nanoscale Materials. In Sustainable Nanoscale Engineering. Edited by: Elsevier; 2020:1-18.

Perspective chapter on sustainability with emphasis on nanomaterials

- 3. Jiang S, Ladewig BP: Green synthesis of polymeric membranes: Recent advances and future prospects. Current Opinion in Green and Sustainable Chemistry 2020, 21:1-8.

Review on recent reports related to green membranes

- 4. RameshKumar S, Shaiju P, O'Connor KE: Bio-based and biodegradable polymers-State-of-the-art, challenges and emerging trends. Current Opinion in Green and Sustainable Chemistry 2020, 21:75-81.

Review on recent work on biobased and biodegradable materials

- 5. Pulido BA, Habboub OS, Aristizabal SL, Szekely G, Nunes SP: Recycled Poly (ethylene terephthalate) for High Temperature Solvent Resistant Membranes. ACS Applied Polymer Materials 2019, 1:2379-2387.

Membrane preparation method using a polymer recycled in large scale

-6. Aristizábal SL, Chisca S, Pulido BA, Nunes SP: Preparation of PEEK membranes with excellent stability using common organic solvents. Industrial \& Engineering Chemistry Research 2019, 59:5218-5226.

Procedure to prepare membranes using the solvent stable PEEK under mild non-corrosive conditions

7. Singh M, Haring AP, Tong Y, Cesewski E, Ball E, Jasper R, Davis EM, Johnson BN: Additive manufacturing of mechanically isotropic thin films and membranes via microextrusion 3D printing of polymer solutions. ACS applied materials \& interfaces 2019, 11:6652-6661.

8. Dommati H, Ray SS, Wang J-C, Chen S-S: A comprehensive review of recent developments in 3D printing technique for ceramic membrane fabrication for water purification. RSC advances 2019, 9:16869-16883.

-9. Sabirova A, Pisig F, Rayapuram N, Hirt H, Nunes SP: nanofabrication of isoporous Membranes for cell fractionation. Scientific reports 2020, 10:1-9.

Combination of lithographic methods for preparation of isoporous UF-MF membranes applicable to a wide range of polymeric materials

10. te Brinke E, Achterhuis I, Reurink DM, de Grooth J, de Vos WM: Multiple approaches to the buildup of asymmetric polyelectrolyte multilayer membranes for efficient water purification. ACS Applied Polymer Materials 2020, 2:715-724.

•• 11. Baig MI, Durmaz EN, Willott JD, de Vos WM: Sustainable Membrane Production through Polyelectrolyte Complexation Induced Aqueous Phase Separation. Advanced Functional Materials 2020, 30:1907344.

Membrane fabrication using water as solvent and $\mathrm{pH}$ induced phase separation.

- 12. Kamp J, Emonds S, Borowec J, Restrepo Toro MA, Wessling M: On the organic solvent free preparation of ultrafiltration and nanofiltration membranes using polyelectrolyte complexation in an all aqueous phase inversion process. Journal of Membrane Science 2021, 618:118632. 
Membrane fabrication using water as solvent and salt-induced phase separation.

13. Sadman K, Delgado DE, Won Y, Wang Q, Gray KA, Shull KR: Versatile and High-Throughput Polyelectrolyte Complex Membranes via Phase Inversion. ACS Applied Materials \& Interfaces 2019, 11:16018-16026.

14. Aburabie JH, Puspasari T, Peinemann K-V: Alginate-based membranes: Paving the way for green organic solvent nanofiltration. Journal of Membrane Science 2020, 596:117615.

15. Rasool MA, Van Goethem C, Vankelecom IF: Green preparation process using methyl lactate for cellulose-acetate-based nanofiltration membranes. Separation and Purification Technology 2020, 232:115903.

- 16. Ong C, Falca G, Huang T, Liu J, Manchanda P, Chisca S, Nunes SP: Green Synthesis of Thin-Film Composite Membranes for Organic Solvent Nanofiltration. ACS Sustainable Chemistry \& Engineering 2020, 8: 11541-11548.

Substitution of organic phase solvent in interfacial polymerization by a bio-sourced solvent.

17. Dong X, Shannon HD, Parker C, De Jesus S, Escobar IC: Comparison of two low-hazard organic solvents as individual and cosolvents for the fabrication of polysulfone membranes. AlChE Journal 2020, 66:e16790.

- 18. Rasool MA, Vankelecom I: Use of $\boldsymbol{y}$-valerolactone and glycerol derivatives as bio-based renewable solvents for membrane preparation. Green chemistry 2019, 21:1054-1064.

Use of a series of bio-sourced solvents for membranes

- 19. Marino T, Galiano F, Molino A, Figoli A: New frontiers in sustainable membrane preparation: Cyrene $^{\mathrm{TM}}$ as green bioderived solvent. Journal of Membrane Science 2019, 580:224-234.

Membrane preparation using bio-sourced solvent

20. Russo F, Galiano F, Pedace F, Aricò F, Figoli A: Dimethyl isosorbide as a green solvent for sustainable ultrafiltration and microfiltration membrane preparation. ACS Sustainable Chemistry \& Engineering 2019, 8:659-668.

21. Gronwald O, Weber M: AGNIQUE AMD 3L as green solvent for polyethersulfone ultrafiltration membrane preparation. Journal of Applied Polymer Science 2020, 137:48419.

22. Byrne FP, Nussbaumer CM, Savin EJ, Milescu RA, McElroy CR, Clark JH, van Vugt-Lussenburg BMA, van der Burg B, Meima MY, Buist HE, et al.: A Family of Water-Immiscible, Dipolar Aprotic, Diamide Solvents from Succinic Acid. 2020, 13:3212-3221.

23. Rasool MA, Vankelecom IFJ: Preparation of full-bio-based nanofiltration membranes. Journal of Membrane Science 2021, 618:118674.

24. Russo F, Galiano F, Pedace F, Aricò F, Figoli A: Dimethyl Isosorbide As a Green Solvent for Sustainable Ultrafiltration and Microfiltration Membrane Preparation. ACS Sustainable Chemistry \& Engineering 2020, 8:659-668.

25. Verheijen M, Lienhard M, Schrooders Y, Clayton O, Nudischer R, Boerno S, Timmermann B, Selevsek $\mathrm{N}$, Schlapbach R, Gmuender H: DMSO induces drastic changes in human cellular processes and epigenetic landscape in vitro. Scientific reports 2019, 9:1-12.

26. Alexowsky C, Bojarska M, Ulbricht M: Porous poly(vinylidene fluoride) membranes with tailored properties by fast and scalable non-solvent vapor induced phase separation. Journal of Membrane Science 2019, 577:69-78.

27. Marino T, Galiano F, Simone S, Figoli A: DMSO EVOL ${ }^{\mathrm{TM}}$ as novel non-toxic solvent for polyethersulfone membrane preparation. Environmental Science and Pollution Research 2019, 26:14774-14785.

28. Ursino C, Russo F, Ferrari RM, De Santo MP, Di Nicolò E, He T, Galiano F, Figoli A: Polyethersulfone hollow fiber membranes prepared with Polarclean ${ }^{\circledR}$ as a more sustainable solvent. Journal of Membrane Science 2020, 608:118216. 
29. Wang HH, Jung JT, Kim JF, Kim S, Drioli E, Lee YM: A novel green solvent alternative for polymeric membrane preparation via nonsolvent-induced phase separation (NIPS). Journal of Membrane Science 2019, 574:44-54.

30. Xie W, Tiraferri A, Liu B, Tang P, Wang F, Chen S, Figoli A, Chu L-Y: First Exploration on a Poly(vinyl chloride) Ultrafiltration Membrane Prepared by Using the Sustainable Green Solvent PolarClean. ACS Sustainable Chemistry \& Engineering 2020, 8:91-101.

- 31. Jung JT, Wang HH, Kim JF, Jeon SM, Park SH, Lee WH, Moon SJ, Drioli E, Lee YM: Microfiber aligned hollow fiber membranes from immiscible polymer solutions by phase inversion. Journal of Membrane Science 2020, 617:118654.

Highly porous membranes prepared by blending polymers

32. Ajari H, Chaouachi B, Galiano F, Marino T, Russo F, Figoli A: A novel approach for dissolving crystalline LDPE using non-toxic solvents for membranes preparation. International Journal of Environmental Science and Technology 2019, 16:5375-5386.

- 33. Rasool MA, Pescarmona PP, Vankelecom IF: Applicability of organic carbonates as green solvents for membrane preparation. ACS Sustainable Chemistry \& Engineering 2019, 7:13774-13785.

Comparison of a series of carbonates as solvents for membranes

34. Le Phuong HA, Izzati Ayob NA, Blanford CF, Mohammad Rawi NF, Szekely G: Nonwoven Membrane Supports from Renewable Resources: Bamboo Fiber Reinforced Poly(Lactic Acid) Composites. ACS Sustainable Chemistry \& Engineering 2019, 7:11885-11893.

35. Mariën $\mathrm{H}$, Vankelecom IFJ: Optimization of the ionic liquid-based interfacial polymerization system for the preparation of high-performance, low-fouling RO membranes. Journal of Membrane Science 2018, 556:342-351.

- 36. Kim D, Livazovic S, Falca G, Nunes SP: Oil-Water Separation using Membranes Manufactured from Cellulose/lonic Liquid Solutions. ACS Sustainable Chemistry \& Engineering 2019, 7:56495659.

Cellulose membrane tested for produced water and review of characteristics and toxicity of ionic liquids

37. Durmaz EN, Çulfaz-Emecen PZ: Cellulose-based membranes via phase inversion using [EMIM] OACDMSO mixtures as solvent. Chemical Engineering Science 2018, 178:93-103.

38. Falca G, Musteata V-E, Behzad AR, Chisca S, Nunes SP: Cellulose hollow fibers for organic resistant nanofiltration. Journal of Membrane Science 2019, 586:151-161.

38. Berton P, Shen X, Rogers RD, Shamshina JL: 110th Anniversary: High-Molecular-Weight Chitin and Cellulose Hydrogels from Biomass in lonic Liquids without Chemical Crosslinking. Industrial \& Engineering Chemistry Research 2019, 58:19862-19876.

39. Shamshina JL, Zavgorodnya O, Choudhary H, Frye B, Newbury N, Rogers RD: In Search of Stronger/Cheaper Chitin Nanofibers through Electrospinning of Chitin-Cellulose Composites Using an lonic Liquid Platform. ACS Sustainable Chemistry \& Engineering 2018, 6:14713-14722.

40. Kim D, Nunes SP: Poly (ether imide sulfone) Membranes from Solutions in lonic Liquids. Industrial \& Engineering Chemistry Research 2017, 56:14914-14922.

41. Hua D, Japip S, Wang KY, Chung T-S: Green design of poly (m-phenylene isophthalamide)-based thin-film composite membranes for organic solvent nanofiltration and concentrating lecithin in hexane. ACS Sustainable Chemistry \& Engineering 2018, 6:10696-10705.

42. Kim D, Salazar OR, Nunes SP: Membrane manufacture for peptide separation. Green Chemistry 2016, 18:5151-5159.

- 43. Chisca S, Marchesi T, Falca G, Musteata V-E, Huang T, Abou-Hamad E, Nunes SP: Organic solvent and thermal resistant polytriazole membranes with enhanced mechanical properties cast from solutions in non-toxic solvents. Journal of Membrane Science 2020, 597:117634.

Sponge morphology and high stability membrane obtained with ionic liquid; mechanical investigation 
44. Yan $X$, Anguille $S$, Bendahan $M$, Moulin P: Ionic liquids combined with membrane separation processes: A review. Separation and Purification Technology 2019, 222:230-253.

45. Dunn CA, Shi Z, Zhou R, Gin DL, Noble RD: (Cross-Linked Poly(Ionic Liquid)-Ionic Liquid-Zeolite) Mixed-Matrix Membranes for $\mathrm{CO} / \mathrm{CH} 4$ Gas Separations Based on Curable Ionic Liquid Prepolymers. Industrial \& Engineering Chemistry Research 2019, 58:4704-4708.

46. Maciel VG, Wales DJ, Seferin M, Ugaya CML, Sans V: State-of-the-art and limitations in the life cycle assessment of ionic liquids. Journal of Cleaner Production 2019, 217:844-858.

47. Perna FM, Vitale $P$, Capriati V: Deep eutectic solvents and their applications as green solvents. Current Opinion in Green and Sustainable Chemistry 2020, 21:27-33.

48. Craveiro R, Neves LA, Duarte ARC, Paiva A: Supported liquid membranes based on deep eutectic solvents for gas separation processes. Separation and Purification Technology 2021, 254:117593.

49. Maalige R N, Dsouza SA, Pereira MM, Polisetti V, Mondal D, Nataraj SK: Introducing deep eutectic solvents as flux boosting and surface cleaning agents for thin film composite polyamide membranes. Green Chemistry 2020, 22:2381-2387.

50. Hu Y, Liu L, Yu J, Wang Z, Fan Y: Preparation of Silk Nanowhisker-Composited Amphoteric Cellulose/Chitin Nanofiber Membranes. Biomacromolecules 2020, 21:1625-1635.

51. Smink D, Juan A, Schuur B, Kersten SRA: Understanding the Role of Choline Chloride in Deep Eutectic Solvents Used for Biomass Delignification. Industrial \& Engineering Chemistry Research 2019, 58:16348-16357. 
7 October 2020

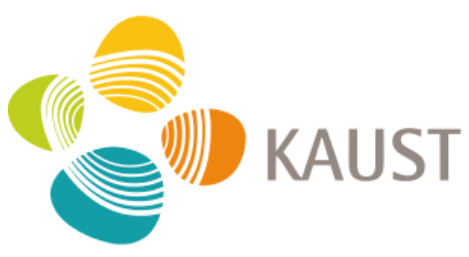

\section{$\underline{\text { Declaration of Interest Statement }}$}

"Green solvents for membrane manufacture: Recent trends and perspectives", by Dooli Kim and Suzana Nunes

The authors declare no conflict of interest

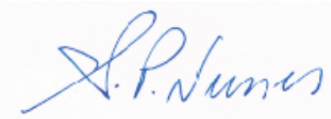

Suzana P. Nunes

Professor of Chemical and Environmental Science and Engineering

King Abdullah University of Science and Technology (KAUST)

npm.kaust.edu.sa

Email: Suzana.nunes@kaust.edu.sa, Mobile+966544700052 